\title{
Stabilization of ribofuranose by a mineral surface
}

\author{
Thomas Georgelin $^{\mathrm{a}, *}$, Maguy Jaber ${ }^{\mathrm{a}}$, Frédéric Fournier ${ }^{\mathrm{a}}$, Guillaume Laurent ${ }^{\mathrm{b}}$, France Costa-Torro ${ }^{\mathrm{a}}$, \\ Marie-Christine Maurel ${ }^{c}$, Jean-Francois Lambert ${ }^{\mathrm{a}, *}$ \\ a Laboratoire de Réactivité de Surface, CNRS UMR-7197, UPMC Univ Paris 06, 3 Rue Galilée, 94200 Ivry sur Seine, France \\ ${ }^{\mathrm{b}}$ Laboratoire de Chimie de la Matiere Condensée de Paris, UPMC Univ Paris 06, CNRS UMR 7574, Collège de France, 11 place Marcelin Berthelot, 75005 Paris, France \\ ${ }^{\mathrm{C}}$ UMR 7205-ISyEB, CNRS-MNHN-UPMC Univ Paris 06, F-75005 Paris, France
}

Keywords:

Prebiotic chemistry

RNA world

D-Ribose

Silica

Mineral surfaces

\begin{abstract}
A B S T R A C T
The existence of the ribose moiety in biomolecules poses two problems for prebiotic chemistry. First, the exclusive presence of the furanose isomer in RNA has to be accounted for since furanose is a minor form in solution and does not exist in crystals. Second, all D-ribose polymorphs are unstable in aqueous medium so that a stabilization mechanism has to be invoked. We observed that the adsorption on mineral surfaces as amorphous silica protects the sugar from degradation processes. Moreover, this silica surface, used as realistic chert model, is able to increase significantly the proportion of ribofuranose compared to ribopyranose forms. The interaction between surface and sugar was analyzed by ${ }^{13} \mathrm{C}$ NMR. Our results show a very significant chemical and thermal stabilization of the adsorbed sugar by a silica surface and an almost twofold increase of ribofuranose compared to ribose in solution.
\end{abstract}

Ribose, a simple sugar with the formula $\mathrm{C}_{5} \mathrm{H}_{10} \mathrm{O}_{5}$, is a major component of the nucleotides that form RNA. In the context of prebiotic chemistry, its synthesis, stabilization, and chemical reactivity are particularly interesting, especially to assess the 'RNA World' hypothesis. ${ }^{1}$

In this scenario, autocatalytic and informational RNA molecules are the first complex biopolymers to have emerged and provide a missing link between small molecules and living organisms. Even though interesting chemical pathways leading to the synthesis of nucleotides have been proposed that need not go through the free sugar, ${ }^{2}$ it remains legitimate to wonder how the sugar component could have arisen. It could have been synthesized prebiotically by the formose reaction, ${ }^{3}$ based on the polymerization of formaldehyde and first evidenced by Butlerow in 1861, although as a rather minor product of this reaction. ${ }^{4}$ It is not enough to form ribose however, since a problem of isomer selection is encountered. Ribose presents four polymorphs, two with a pyranose and two with a furanose ring (scheme 1). Only the $\beta$-furanose form is used in RNA molecules. Moreover, D-ribose is unstable in solution. For example, at pH 9 and $60{ }^{\circ} \mathrm{C}$, its half life is about $50 \mathrm{~h}$; in more physiological conditions, at pH 7 and $37^{\circ} \mathrm{C}$, it should be around $500 \mathrm{~h}$ if one extrapolates from the data of Miller and co-workers. ${ }^{5}$ In the

\footnotetext{
* Corresponding authors.

E-mail addresses: thomas.georgelin@upmc.fr (T. Georgelin), jean-francois lambert@upmc.fr (J.-F. Lambert).
}

solid state, the furanose form does not exist. ${ }^{6}$ Thus, two questions need to be answered: (i) how have the ribofuranose forms emerged and been selected to form RNA molecules; (ii) how has this sugar been stabilized in solution? A tentative answer to the second question is that borate complexes could have acted as ribose stabilizing agent. ${ }^{3,7}$ At least two studies have claimed that silicates in solution can also stabilize ribose during the formose reaction. ${ }^{8}$ Although this has not been observed in another experimental investigation, ${ }^{9}$ theoretical studies have confirmed that the ribose-silicate $2: 1$ complex is more stable than other pentose and hexose complexes, a concept experimentally verified by Lambert et al., and constituting a first example of selectivity of interaction between mineral centers and sugars. ${ }^{8 a}$ Furthermore, theoretical results have also shown that silicate complexes should be formed exclusively with the furanose form because in the latter form, the $\mathrm{HO}-\mathrm{C}-\mathrm{C}-\mathrm{OH}$ dihedral angle is sufficiently small to allow the formation of a planar five-membered ring ${ }^{8 a}$ including the silicon atom, so that the silicate scenario could also help answer our question. (i) Since interaction with silicate is possible in solution, a third question can be asked: (iii) could silica or silicate surfaces have played a role in the emergence and stabilization of ribose and more specifically of ribofuranose? The influence of mineral surfaces on the formose reaction has been previously addressed. ${ }^{10}$ Montmorillonite, calcite, hydroxyapatite and alumina seem to promote the formation, in minor proportions, of unbranched aldoses. In these studies, no selectivity of condensation for specific ribose polymorphs was 
<smiles>O[C@H]1CO[C@H](O)[C@@H](O)[C@H]1O</smiles>

$\alpha$-pyranose<smiles>OC[C@H]1O[C@H](O)[C@@H](O)[C@@H]1O</smiles>

$\alpha$-furanose<smiles>OC1=C(O)[C@H](O)[C@@H](O)CO1</smiles><smiles>OC[C@H]1OC(O)=C(O)[C@@H]1O</smiles>

$\beta$-furanose $\beta$-pyranose

Scheme 1. Ribose polymorphs.

observed. Of course, chemical analysis of minor products in a complex mixture is difficult and it seems necessary as a first step to analyze more precisely the interaction between monosaccharides and different mineral surfaces. In this respect, a few studies have analyzed the adsorption of ribose and nucleoside on clay mineral surfaces. ${ }^{11}$ For example, Aisawa et al. ${ }^{11 a}$ have adsorbed ribose on anionic clay minerals (LDH). The intercalation of ribose was observed in the interlayer space of clay, and it was claimed that the furanose form predominated, but the possible stabilization toward degradation was not discussed.

The present work focused on the interaction of ribose with an amorphous silica $\left(\mathrm{SiO}_{2}\right)$ with a high surface area $\left(380 \mathrm{~m}^{2} / \mathrm{g}\right)$, Aerosil 380 , and its relation to isomer selectivity and stability. Silica represents a possible model of mineral phases existing on the primitive earth such as cherts (microcrystalline silica-containing sedimentary rocks), and in addition organic species supported on it are easy to characterize. ${ }^{12}$ We indeed observed that ribose confinement by adsorption on this surface significantly shifts the isomerization equilibrium to furanose and in addition stabilizes the adsorbed sugar against degradation.

\section{Experimental}

Ribose was provided by Sigma. Aerosil $380\left(\mathrm{SiO}_{2}\right)$ was provided by Evonik. It is a non-porous fumed silica with a BET surface area of $380 \mathrm{~m}^{2} / \mathrm{g}$.

\subsection{Adsorption procedures}

Ribose adsorption was carried out by impregnation or by selective adsorption methods. In the impregnation procedure, $300 \mathrm{mg}$ of silica was wetted with a ribose solution $(3.3 \mathrm{~mL})$. The obtained paste was stirred at room temperature for $3 \mathrm{~h}$ and dried at $70{ }^{\circ} \mathrm{C}$ in an oven. In the selective adsorption procedure, $300 \mathrm{mg}$ of silica was dispersed in $25 \mathrm{mM}$ ribose for $3 \mathrm{~h}$ at room temperature and stored at $70^{\circ} \mathrm{C}$ for $150 \mathrm{~h}$ at $\mathrm{pH} 9$. The solid phase was separated from the liquid phase by centrifugation, and then dried at $30^{\circ} \mathrm{C}$.

\subsection{Analytical techniques}

$-{ }^{13} \mathrm{C}$ NMR: HP-DEC sequences (proton high power decoupling) were recorded at room temperature with a Bruker Avance 300 spectrometer with a field of $11.8 \mathrm{~T}$ equipped with a $4 \mathrm{~mm}$ MAS probe with a spinning rate of $10 \mathrm{kHz}$. The pulse angle was $30^{\circ}$, decoupling was applied at $50 \mathrm{KHz}$, and the recycle time was $10 \mathrm{~s}$. CP-MAS sequences were recorded at room temperature on the same apparatus. The contact time was $1000 \mu \mathrm{s}$ (other values were tested as well, see Supplementary information) The recycle time was $1 \mathrm{~s}$ for adsorbed ribose and $300 \mathrm{~s}$ for bulk ribose.
- TGA of the samples was carried out on a TA Instruments Waters LLC, with a SDT Q600 analyzer, using a heating rate $\tau=5^{\circ} \mathrm{C} / \mathrm{min}$ under dry air flow (100 mL/min).

\section{Results and discussion}

TGA (thermogravimetric analysis) of bulk D-ribose shows an endothermic event without weight change at $90{ }^{\circ} \mathrm{C}$, due to ribose melting, ${ }^{13}$ followed by four weight-loss events $\left(195^{\circ} \mathrm{C}\right.$, about $20 \%$, endothermic; $280^{\circ} \mathrm{C}$, weakly exothermic, and $320^{\circ} \mathrm{C}$, strongly exothermic, $51 \%$; and $510{ }^{\circ} \mathrm{C}$, around $29 \%$, strongly exothermic and resulting in complete combustion; Fig. 1 and SI-Fig. 1). Here we do not intend to discuss these events in detail but to use them as a fingerprint. The endothermic weight loss at the low temperature of $195^{\circ} \mathrm{C}$ could suggest ribose polymerization with water elimination, but complete linear polymerization would result in a $13 \%$ weight loss while the observed value is almost twice higher.

Since we were interested in ribose stability, we also left a $60 \mathrm{mM}$ ribose solution to dry in an oven at $70^{\circ} \mathrm{C}$ (i.e., in the same conditions as used later for the preparation of ribose/silica, but without addition of any silica). The final product was a brown gel. This material had clearly undergone significant chemical modifications with respect to the starting ribose. Thus, its TG (see Supporting information) was totally different from that of ribose, and in particular did not show any melting transition at $95^{\circ} \mathrm{C}$, indicating that the drying process had caused significant modifications in the ribose structure and confirming the wellknown thermal instability of the latter molecule. The brown gel obtained from drying of the ribose solution at $70{ }^{\circ} \mathrm{C}$ shows significant modifications in its ${ }^{13} \mathrm{C}$ solid-state NMR spectrum (see below), indicative of ribose degradation. New peaks appear at $107 \mathrm{ppm}$ and below $100 \mathrm{ppm}$, corresponding to new carbon environments, and carbonyl environments appear at $180 \mathrm{ppm}$, probably corresponding to the linear form of the ribose.

Ribose was then adsorbed onto silica (with a 10 weight\% loading, see Section 1), submitted to oven drying at $70{ }^{\circ} \mathrm{C}$, and its thermal reactivity investigated. Between $20^{\circ} \mathrm{C}$ and $110^{\circ} \mathrm{C}$, a large amount of water was eliminated, indicating that the apparently dry sample actually contained no less than $32 \%$ weakly held water. Two broad thermal events were observed at higher temperatures: the first one with a $T_{\max }=185^{\circ} \mathrm{C}$ is almost athermic and corre-

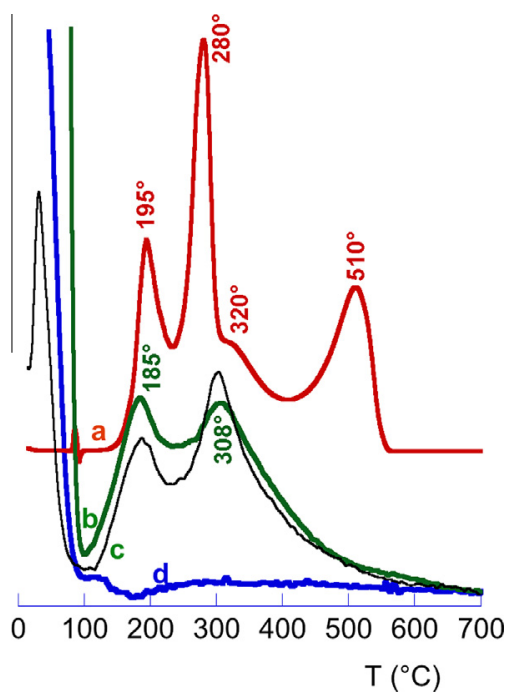

Figure 1. DTG (derivative of thermogravimetric signal) of bulk D-ribose (a), 10 weight\% D-ribose on silica dried under air (b), the same dried under vacuum (c), the dried silica support (blank, d). 
sponds to the loss of about $5 \%$ of the support weight; the second one, clearly exothermic, with a $T_{\max }=308{ }^{\circ} \mathrm{C}$, corresponds to the loss of about $9 \%$ of the support weight (SI-Fig. 2). The total weight loss corresponds to the elimination of all the ribose (10\%), plus a significant amount of rather strongly held hydration water. The significant temperature shifts as compared to bulk ribose reveal a specific interaction of the ribose molecules with the silica surface in the dry state.

One of the conclusions that may be drawn from these results is that ribose on silica, when dried under ambient air, retains a large amount of water-in fact enough water to dissolve the ribose to a $1.3 \mathrm{M}$ solution. One could speak therefore of a supported solution or maybe a supported syrup.

We have attempted to dry the sample in more severe conditions, under vacuum at $50{ }^{\circ} \mathrm{C}$. This resulted in a 15 -fold reduction of weakly held water with respect to the air-dried sample: physisorbed water amounted in this case to only 3.0 molecules per $\mathrm{nm}^{2}$, definitely below the monolayer, so that one no longer speaks of a supported solution phase. The higher-temperature part of the TG was very similar to that of the air-dried sample (compare Fig. 1c and $\mathrm{b}$ ). Since the ribose is not in solution after vacuum drying, it could either be adsorbed on the surface or precipitated as a bulk phase. In fact X-ray diffractometry shows no bulk ribose peaks, be it after air-drying or vacuum drying. Therefore ribose can be molecularly adsorbed on the silica surface at least up to a loading of $10 \% \mathrm{w}$. On the basis of the silica surface area, such a loading corresponds to 1.05 molecules per $\mathrm{nm}^{2}$.

In contrast to the brown gel obtained from drying the solution, the air-dried ribose/silica sample was white, and remained so even after drying under vacuum. This simple observation is not sufficient to establish that ribose is stabilized by its interaction with the surface; molecular-level information is needed. Figure 2 compares the solid-state ${ }^{13} \mathrm{C}$ NMR spectra of bulk ribose, and the two ribose/silica samples. Table 1 lists the peak positions for these three samples, and also for the aqueous ribose solution used in the deposition procedure (liquid-state NMR).

Our data confirm that ${ }^{13} \mathrm{C}$ NMR easily distinguishes between the four isomers of D-ribose. In the bulk solid, only the two pyranose forms were observed, while all four isomers were present in solution (two pyranose and two furanose isomers). The spectrum for bulk solid D-ribose is almost identical to the one reported in, ${ }^{6}$ and corresponds to a 2:1 mixture of the $\beta p$ and $\alpha p$ isomers (with additional small splittings due to the existence of non-equivalent crystallographic positions).
Table 1

Chemical shifts (ppm) observed for ribose in solution, in the bulk and adsorbed onto silica

\begin{tabular}{|c|c|c|c|c|c|c|}
\hline & Form & $\mathrm{C} 1$ & $\mathrm{C} 2$ & $\mathrm{C} 3$ & $\mathrm{C} 4$ & $\mathrm{C} 5$ \\
\hline \multirow[t]{4}{*}{ Ribose aqueous solution } & $\alpha p$ & 92.8 & 69.4 & 68.6 & 66.7 & 62.3 \\
\hline & $\beta p$ & 93.1 & 70.3 & 68.3 & 66.5 & 62.3 \\
\hline & $\alpha f$ & 95.1 & 70.2 & 69.3 & 82.3 & 60.6 \\
\hline & $\beta f$ & 100.0 & 74.0 & 69.7 & 81.8 & 61.7 \\
\hline \multirow[t]{4}{*}{ Bulk ribose } & $\alpha p$ & 92.9 & 71.9 & 68.4 & 66.4 & 56.2 \\
\hline & $\beta p$ & 95.1 & 72.8 & 67.8 & 65.1 & 56.2 \\
\hline & $\alpha f$ & - & - & - & - & - \\
\hline & $\beta f$ & - & - & - & - & - \\
\hline \multirow[t]{4}{*}{ Ribose $/ \mathrm{SiO}_{2}$ air-dried } & $\alpha p$ & 94.5 & 71.1 & 70.1 & 69.4 & 63.8 \\
\hline & $\beta p$ & 94.9 & 72.0 & 69.5 & 68.4 & 63.8 \\
\hline & $\alpha f$ & 97.3 & 72.0 & 70.3 & 84.0 & 63.5 \\
\hline & $\beta \mathrm{f}$ & 102.1 & 76.3 & 71.5 & 83.4 & 64.5 \\
\hline \multirow[t]{4}{*}{ Ribose/ $\mathrm{SiO}_{2}$ vacuum-dried } & $\alpha_{p}$ & 94.4 & 72.6 & 71.1 & 68.5 & 62.2 \\
\hline & $\beta_{\mathrm{p}}$ & 95.3 & 72.6 & 71.1 & 68.5 & 62.2 \\
\hline & $\alpha_{\mathrm{f}}$ & 97.2 & 72.6 & 71.1 & 84 & 58.1 \\
\hline & $\beta_{\mathrm{f}}$ & 102.4 & 75.6 & 71.1 & 83.5 & 62.2 \\
\hline
\end{tabular}

For the air-dried ribose/silica, the NMR peaks are very sharp, more typical actually of liquid-state than of solid-state NMR. This is compatible with the idea that this sample contains a 'supported solution', as deduced from the TGA above, where the molecules retain a high mobility. In contrast, for vacuum-dried ribose/silica, the peaks are much broader but remain compatible with the chemical shifts of ribose, in contrast to the gel obtained from solution drying that was discussed above which indicated degradation products. In particular, no signal is observed in the carbonyl region, and so decyclization does not occur on silica-supported samples.

Thus, only ribose is present on the surface of silica, but in all four of its isomers. This is not surprising for the air-dried sample which shows the same speciation as a concentrated aqueous solution. However even for the air-dried sample, where the ribose molecules interact with the surface of the silica, ribose speciation remains significantly different from that in the bulk solid. In particular, the furanose forms are present; this can be stated with certainty in spite of the low resolution of the NMR spectrum, since the peaks of the $\alpha \mathrm{f}$ and $\beta \mathrm{f}$ isomers are observed in a region $(80-86 \mathrm{ppm})$ where there is no interference with other signals.

A more quantitative analysis of the NMR results can be provided based on the relative intensity of the $\mathrm{C} 1$ peaks. The corresponding ribose specifications are listed in Table 2; also provided for reference is the speciation in bulk liquid-state ribose, from Ref. 6 .

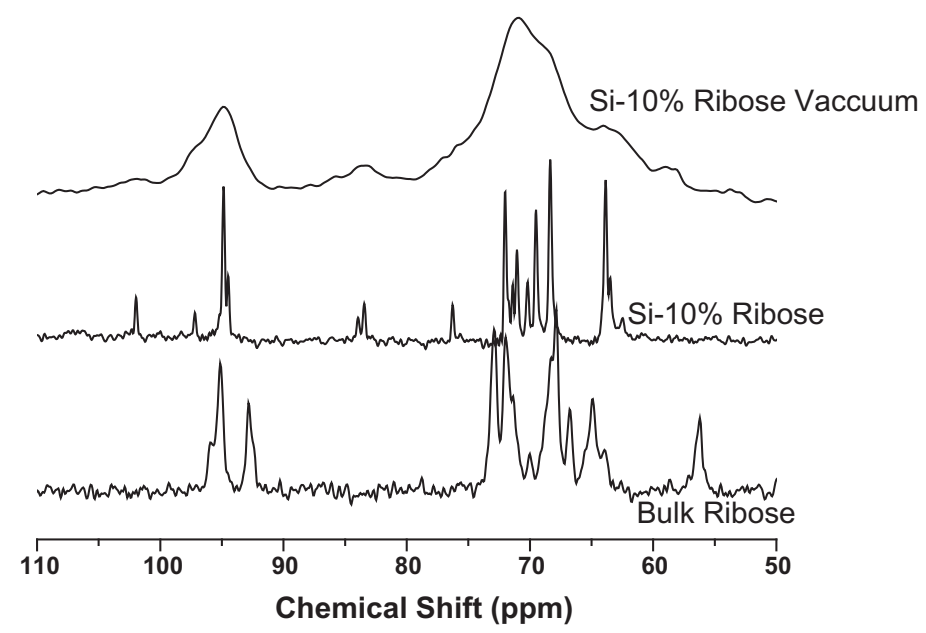

Figure 2. Solid state ${ }^{13} \mathrm{C}$-CP-MAS NMR of bulk D-ribose, ${ }^{13} \mathrm{C}$-HPDEC NMR of air-dried ribose $/ \mathrm{SiO}_{2}$, and ${ }^{13} \mathrm{C}-\mathrm{CP}-\mathrm{MAS}$ of ribose/SiO 2 dried under vacuum. 
Table 2

Ribose isomer distribution (\%) calculated from NMR spectra-C1 area

\begin{tabular}{lrrrr}
\hline$\%$ & $\alpha_{\mathrm{p}}$ & $\beta_{\mathrm{p}}$ & $\alpha_{\mathrm{f}}$ & $\beta_{\mathrm{f}}$ \\
\hline Ribose aqueous solution (liquid state NMR) & 19 & 60 & 8 & 13 \\
Liquid ribose, at melting point ${ }^{6}$ & 25 & 46 & 12 & 17 \\
Ribose $/ \mathrm{SiO}_{2}$ air-dried & 13 & 58 & 12 & 16 \\
Ribose $/ \mathrm{SiO}_{2}$ vacuum-dried & 9 & 48 & 31 & 12 \\
\hline
\end{tabular}

It can be seen that the air-dried ribose/silica contains a somewhat higher percentage of the furanose isomers than the solution used for deposition: $29.1 \%\left(12 \% \alpha_{\mathrm{f}}, 17 \% \beta_{\mathrm{f}}\right)$ versus $21 \%\left(8 \% \alpha_{\mathrm{f}}, 13 \% \beta_{\mathrm{f}}\right)$.

In the vacuum-dried sample, this proportion increases even more, to $43 \%$ furanose ( $31 \% \alpha \mathrm{f}, 12 \% \beta \mathrm{f}$ ). This estimate was obtained from a CP-MAS spectrum, which does not always allow easy quantification. However, we checked that the application of different contact times did not significantly modify the intensity ratios (see Supplementary information, Fig. S5), and besides the carbon atoms whose signals are used for quantification are in very similar chemical environments, compatible with similar polarization transfer dynamics.

When the sample is dehydrated, a direct interaction is probably established between ribose and the silica surface groups (mostly silanols). As shown in Table 2, the strongest shift observed (about $-6 \mathrm{ppm}$, assignment based on relative intensities) was for the C5 of the furanose form $\alpha$. This is probably correlated with the establishment of a specific interaction between the surface and the C5 hydroxyl group of $\alpha$ furanose. This shift is of comparable magnitude, but of opposite sign to that observed for the same carbon in solution when iodide ions interact with ribose-an interaction that presumably does not involve the formation of covalent bonds. ${ }^{14}$ If one form is indeed selectively adsorbed on the silica surface, namely the $\alpha$-furanose isomer, the speciation equilibrium should be displaced toward this form, as is indeed the case.

Finally, we wanted to determine if the stability enhancement of D-ribose by interaction with the surface could be extended to basic and alkaline conditions. A ribose solution at $\mathrm{pH} 9$ ( $\mathrm{pH}$ adjusted with $\mathrm{NaOH}$ ) was stirred in the presence of Aerosil for $150 \mathrm{~h}$ at $70{ }^{\circ} \mathrm{C}$ and the dispersion was dried at $70{ }^{\circ} \mathrm{C}$. The ${ }^{13} \mathrm{C}$ NMR peak positions were the same as for ribose/silica (see Supplementary information), except for the C5 of $\alpha$ - and $\beta$-furanose that were shifted by about $1 \mathrm{ppm}$. No new carbon signals were observed, in particular no signal attributable to the carbonyl group was present at around $170 \mathrm{ppm}$.

According to Larralde et al., ${ }^{5}$ the half-life of ribose in solution at pH 9 should be about $50 \mathrm{~h}$ at $70^{\circ} \mathrm{C}$, while our experiment lasted three times longer. The distribution between the ribose isomers in this case was: pyranose $69 \%\left(54.2 \% \alpha_{p}, 14.4 \% \beta_{p}\right)$, furanose $31 \%$ $\left(20.9 \% \alpha_{\mathrm{f}}, 10.5 \% \beta_{\mathrm{f}}\right)$. These values are very similar to those of the ribose/silica sample discussed above.

\section{Conclusion}

The major result of our work is the stabilization of the D-ribose on the surface of silica, under drying and even under basic conditions. The adsorption and the drying process also significantly increase the proportion of furanose forms compared to ribose in solution. A more complete study on the physical chemistry of adsorbed ribose is underway taking into account the influence of cation complexation, and the relation of furanose and more specifically the $\beta$-D-ribofuranose selection with the formation of nucleobases and their subsequent phosphorylation.

\section{Supplementary data}

Supplementary data (heat flow curves of bulk ribose and adsorbed ribose. Liquid state NMR of D-ribose in $\mathrm{D}_{2} \mathrm{O}$. Comparison of degradated ribose and D-ribose en solution by ${ }^{13} \mathrm{C}$ NMR. DTG of degradated D-ribose. ${ }^{13} \mathrm{C}$-HPDEC NMR of air-dried ribose/silica treated at $\mathrm{pH}$ 9. CP-MAS NMR of vaccum-dried ribose/silica. Evolution as a function of contact time) associated with this article can be found, in the online version, at http://dx.doi.org/10.1016/j.carres. 2014.07.018.

\section{References}

1. Gilbert, W. Nature 1986, 319, 618-618.

2. Ritson, D.; Sutherland, J. D. Nat. Chem. 2012, 4, 895-899.

3. Benner, S. A.; Kim, H.-J.; Carrigan, M. A. Acc. Chem. Res. 2012, 45, $2025-$ 2034.

4. Shapiro, R. Orig. Life Evol. Biosph. 1988, 18, 71-85.

5. Larralde, R.; Robertson, M. P.; Miller, S. L. PNAS 1995, 92, 8158-8160.

6. Sisak, D.; McCusker, L. B.; Zandomeneghi, G.; Meier, B. H.; Blaeser, D.; Boese, R.; Schweizer, W. B.; Gilmour, R.; Dunitz, J. D. Angew. Chem., Int. Ed. 2010, 49 4503-4505.

7. (a) Ricardo, A.; Carrigan, M. A.; Olcott, A. N.; Benner, S. A. Science 2004, 303, 196; (b) Kim, H.-J.; Ricardo, A.; Illangkoon, H. I.; Kim, M. J.; Carrigan, M. A.; Frye, F.; Benner, S. A. J. Am. Chem. Soc. 2011, 133, 9457-9468.

8. (a) Lambert, J. B.; Lu, G.; Singer, S. R.; Kolb, V. M. J. Am. Chem. Soc. 2004, 126 9611-9625; (b) Vazquez-Mayagoitia, A.; Horton, S. R.; Sumpter, B. G.; Sponer, J.; Sponer, J. E.; Fuentes-Cabrera, M. Astrobiology 2011, 11, 115-121.

9. Kim, H.-J.; Benner, S. A. Science 2010, 329. 902-902.

10. (a) Gabel, N. W.; Ponnampe, C. Nature 1967, 216, 453; (b) Reid, C.; Orgel, L. E. Nature 1967, 216, 455; (c) Schwartz, A. W.; Degraaf, R. M. J. Mol. Evol. 1993, 36 101-106.

11. (a) Aisawa, S.; Hirahara, H.; Ishiyama, K.; Ogasawara, W.; Umetsu, Y.; Narita, E. J. Solid State Chem. 2003, 174, 342-348; (b) Carneiro, C. E. A.; Berndt, G.; de Souza Junior, I. G.; de Souza, C. M. D.; Paesano, A., Jr.; da Costa, A. C. S.; di Mauro, E.; de Santana, H.; Zaia, C. T. B. V.; Zaia, D. A. M. Orig. Life Evol. Biosph. 2011, 41, 453-468; (c) Hashizume, H.; Theng, B. K. G. Clays Clay Miner. 2007, 55 , 599-605; (d) Hashizume, H.; van der Gaast, S.; Theng, B. K. G. Clay Miner. 2010, $45,469-475$.

12. Georgelin, T.; Jaber, M.; Onfroy, T.; Hargrove, A.-A.; Costa-Torro, F.; Lambert, J.F. J. Phys. C 2013, 117, 12579-12590.

13. Raemy, A.; Schweizer, T. F. J. Therm. Anal. 1983, 28, 95-108.

14. Ortiz, P.; Fernández-Bertrán, J.; Reguerac, E. Spectrochim. Acta A 2005, 61, 1977 1983. 


\section{Supporting information}

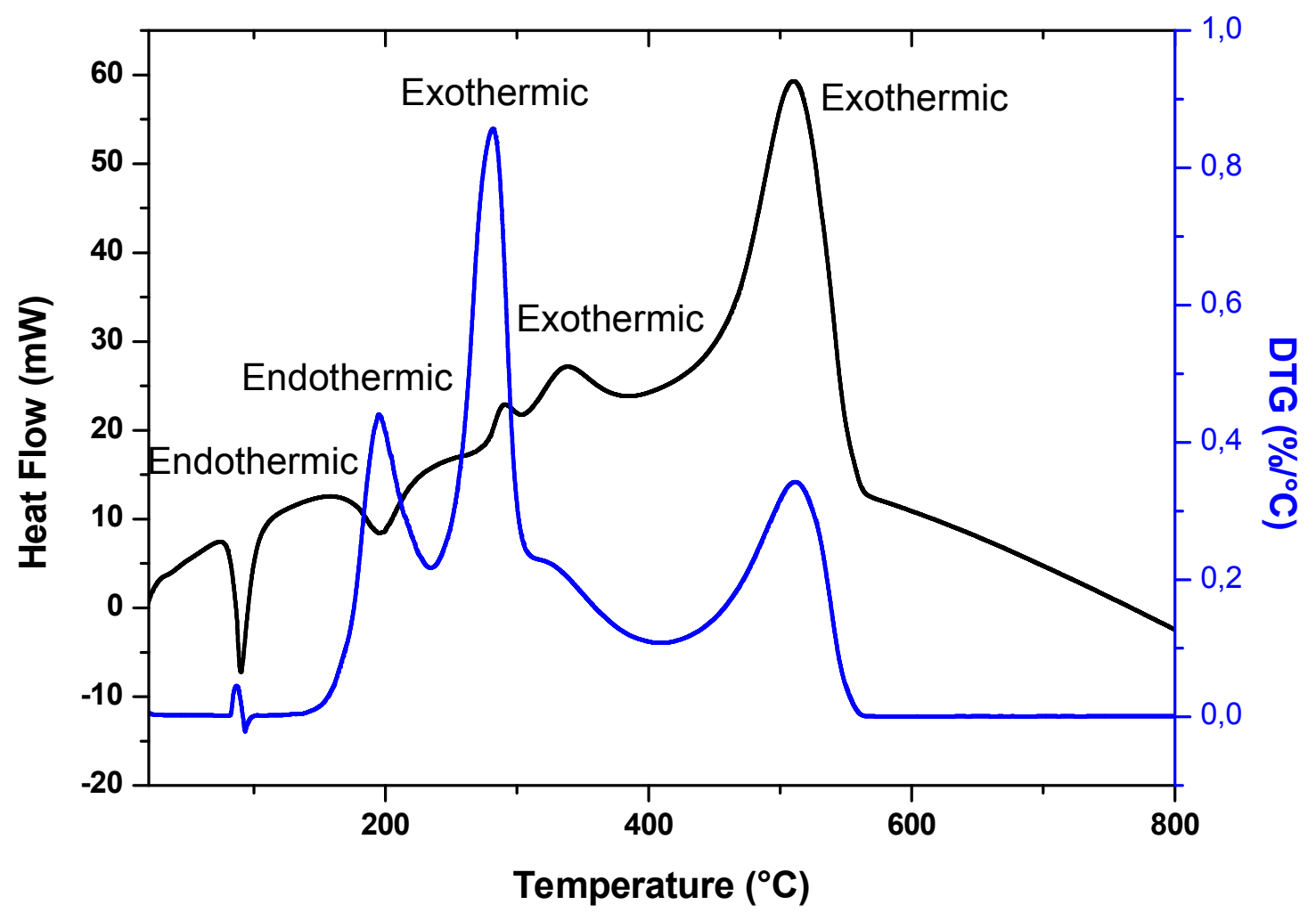

SI-Figure 1 : Bulk Ribose 


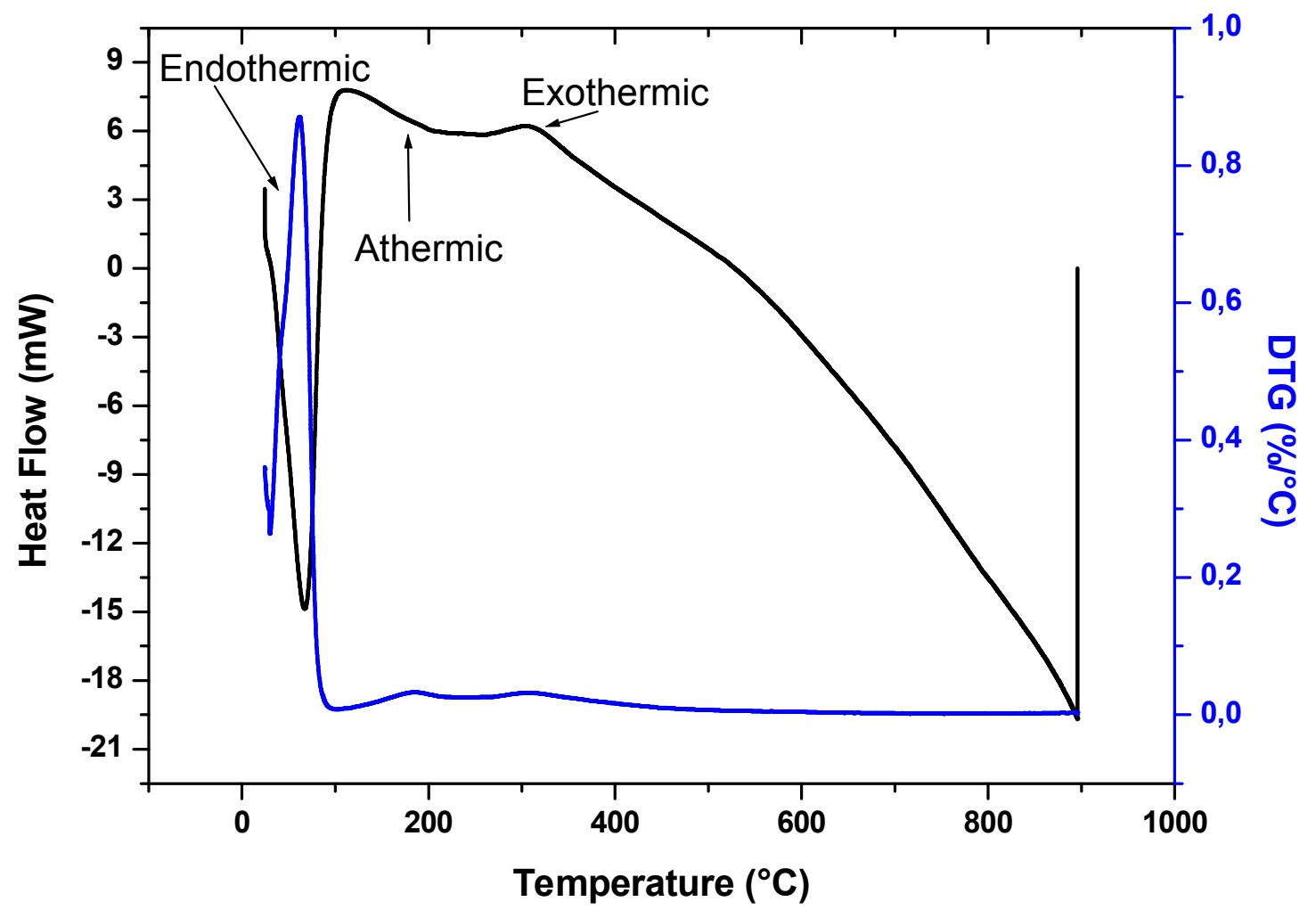

SI-Figure 2 : Adsorbeds ribose 


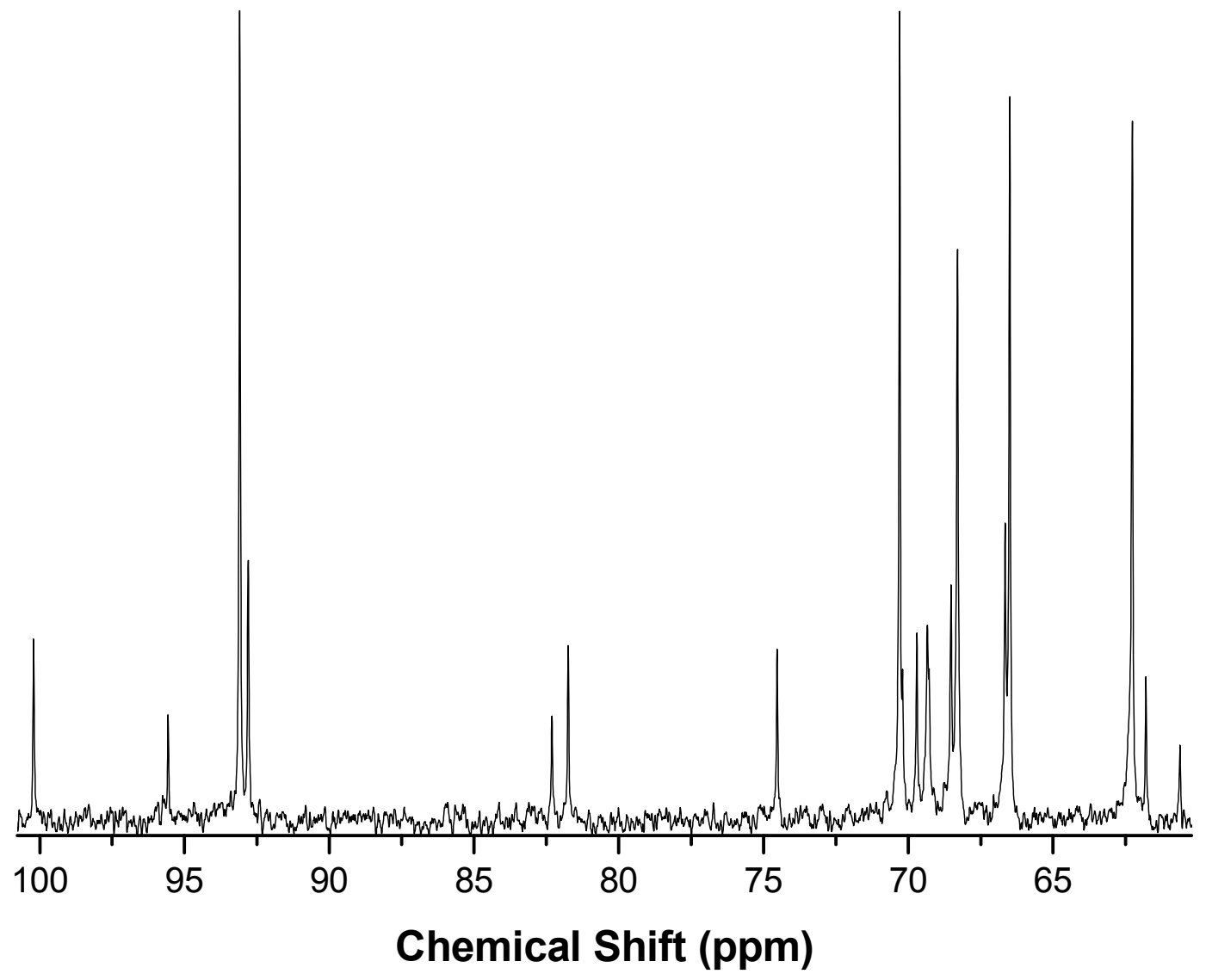

SI-Figure 3 : Liquid state (in $\left.\mathrm{D}_{2} \mathrm{O}\right){ }^{13} \mathrm{C}$ - NMR D-ribose 


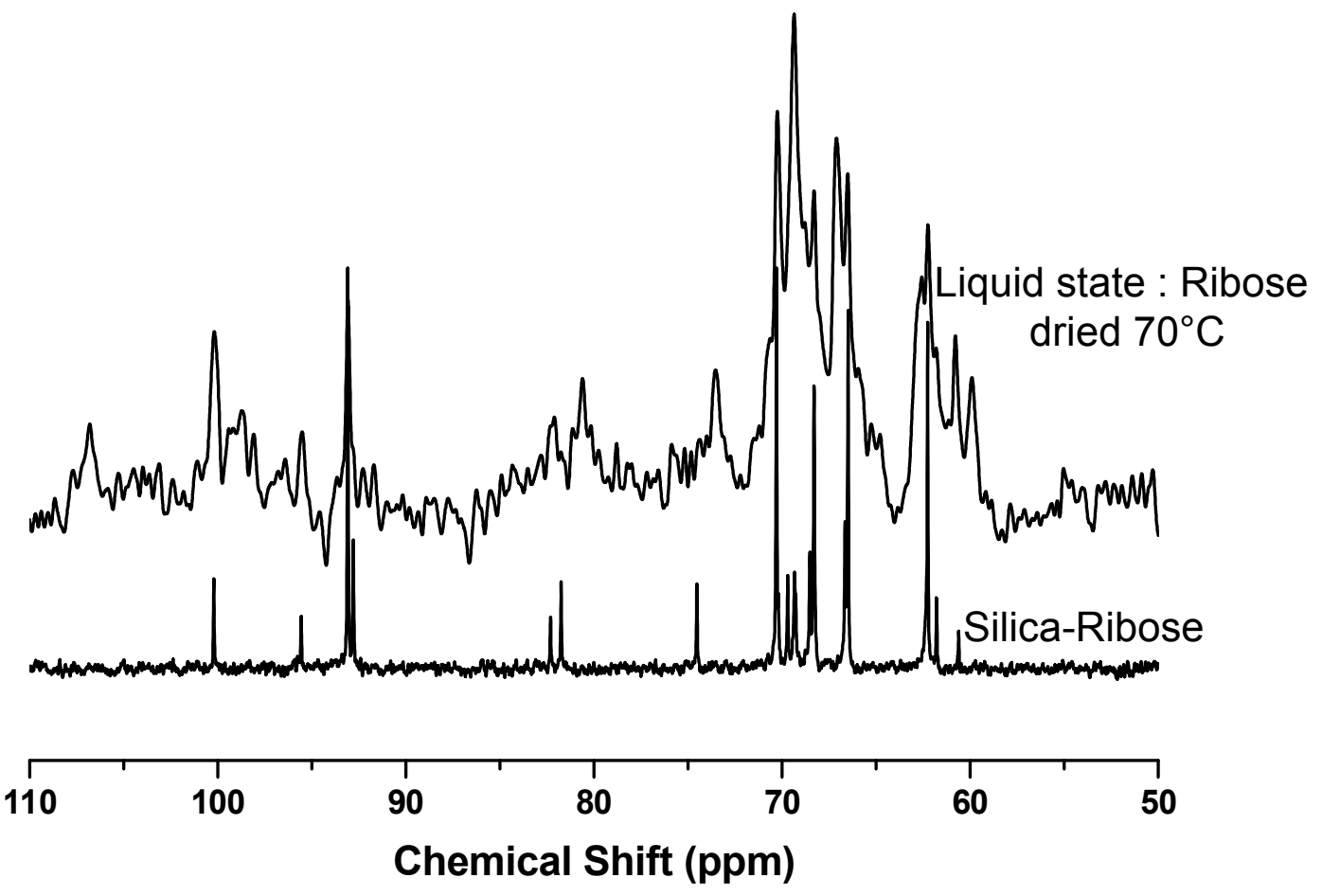

SI-Figure 4 : Liquid state (in $\left.\mathrm{D}_{2} \mathrm{O}\right){ }^{13} \mathrm{C}$ - NMR of solubilised D-ribose treated at $70^{\circ} \mathrm{C}$ (top).

13C-HPDEC NMR of air-dried ribose/silica 


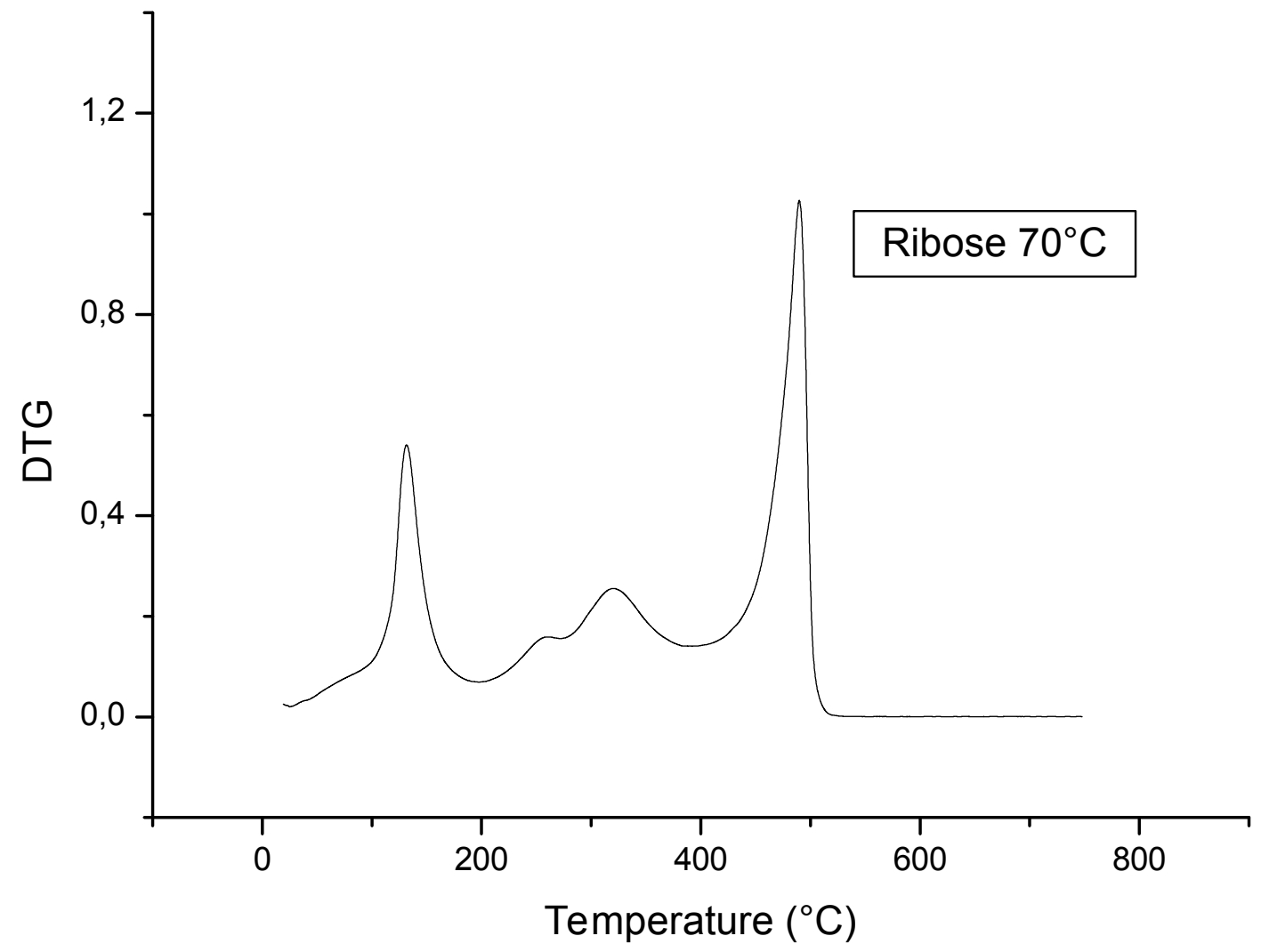

SI-Figure 5 : DTG (derivative of thermogravimetric signal) of D-ribose solubilised and dried at $70^{\circ} \mathrm{C}$. Phase transition analyzed at $90^{\circ} \mathrm{C}$ for non treated ribose is not present in this thermally activated sample. That indicated the evolution of sugar structure. 


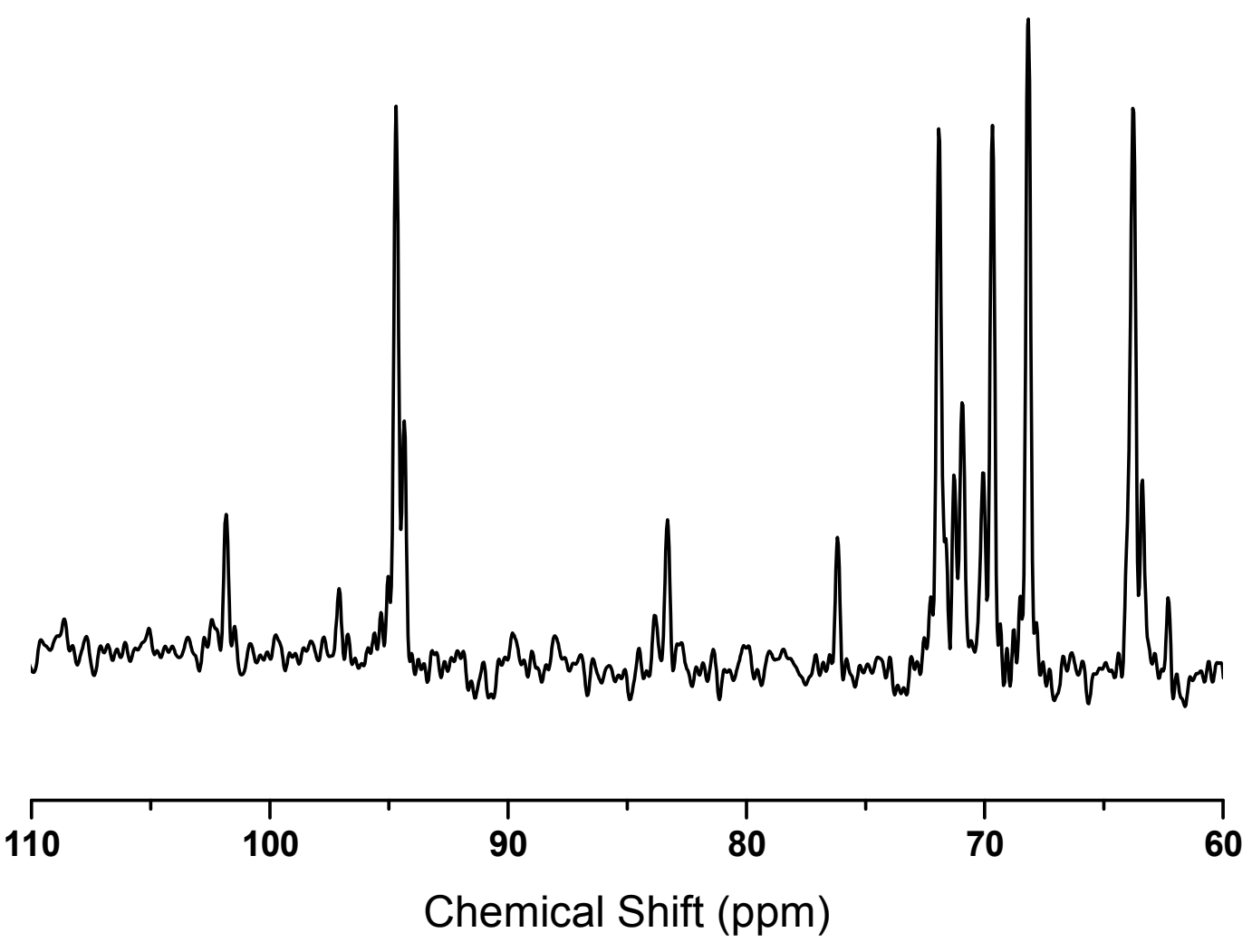

SI-Figure $6:{ }^{13} \mathrm{C}-\mathrm{HPDEC}$ NMR of air-dried ribose/silica. Selective adsorption process - 150h at pH9 


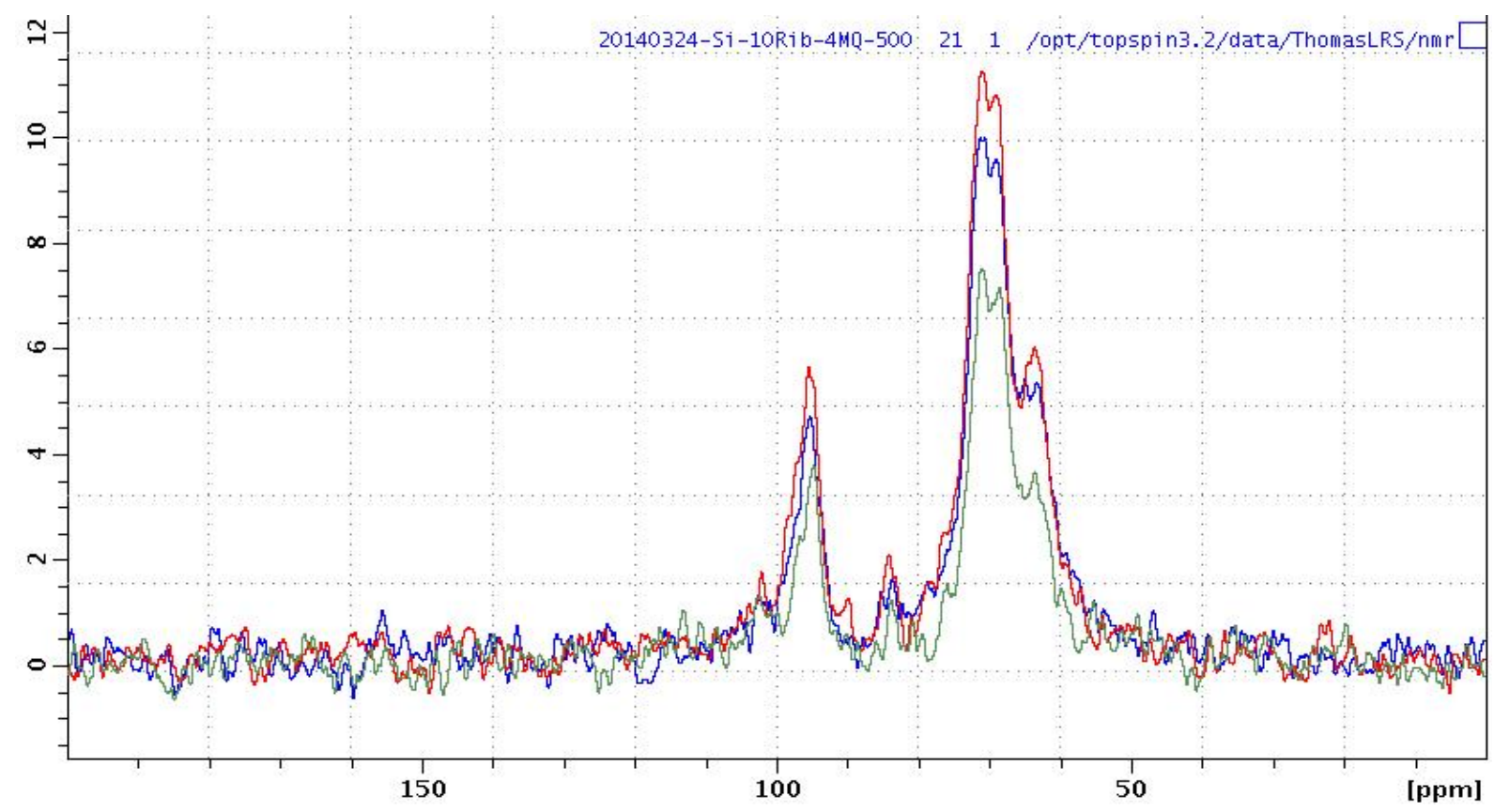

SI-Figure $7:{ }^{13} \mathrm{C}-\mathrm{CPMAS}$ NMR of vaccum-dried ribose/silica. Evolution of contact time at $0,5 \mathrm{~ms}$ (green), $1 \mathrm{~ms}(\mathrm{red})$ and $3 \mathrm{~ms}($ blue). No evolution of peak ratio corresponding to $\alpha / \beta$ pyranose and $\alpha / \beta$ furanose 